Significance of Difference between Minimum Mean Value of Urinary Calcium and that of Other Months in Each Group

\begin{tabular}{|c|c|c|c|c|c|c|c|c|c|c|c|c|c|}
\hline & \multicolumn{12}{|c|}{$\mathbf{P}$} \\
\hline & & Jan. & Feb. & Mar. & Apr. & May & Jun. & Jul. & Aug. & Sept. & Oct. & Nov. & Dec. \\
\hline $\begin{array}{l}\text { Male stone formers } \\
\text { Healthy men } . . \\
\text { Healthy women .. }\end{array}$ & $\begin{array}{l}\because \\
\cdots\end{array}$ & $\frac{\text { N.S. }}{\text { N.S. }}$ & $\begin{array}{l}\text { N.S. } \\
\text { N.S. }\end{array}$ & $\begin{array}{l}<0.005 \\
\text { N.S. } \\
\text { N.S. }\end{array}$ & $\begin{array}{l}<0.005 \\
<0.05 \\
<0.05\end{array}$ & $\begin{array}{l}<0.001 \\
<0.02 \\
<0.005\end{array}$ & $\begin{array}{l}<0.001 \\
<0.005 \\
<0.05\end{array}$ & $\begin{array}{l}<0.001 \\
<0.005 \\
<0.01\end{array}$ & $\begin{array}{l}<0.001 \\
<0.005 \\
<0.001\end{array}$ & $\begin{array}{l}<0.005 \\
<0.05 \\
<0.01\end{array}$ & $\begin{array}{l}<0.05 \\
<0.02 \\
<0.05\end{array}$ & $\begin{array}{l}\text { N.S. } \\
<0.01 \\
\text { N.S. }\end{array}$ & N.S. \\
\hline
\end{tabular}

N.S. $=$ Not significant.

population who excrete, on everage, about $75 \mathrm{mg} /$ day more calcium than those who do not form stones. This difference also existed throughout the year.

One possible cause of the seasonal variation in urinary calcium might be dietary changes in calcium intake. This is unlikely, however, since to increase urinary calcium by 120 $150 \mathrm{mg} /$ day would require, on average, at least a threefold increase in calcium intake in summer over that in winter (Peacock and Nordin, 1969).

Since the seasonal changes in urinary calcium seem to follow the monthly pattern of hours of sunshine it is tempting to speculate that vitamin $\mathrm{D}$ may cause the summer peak of calcium excretion through its effect on the intestinal absorption of calcium. Most reports have shown, however, that the peak in the serum level of 25-hydroxycholecalciferol occurs in late summer (McLaughlin et al., 1974; Stamp and Round, 1974), a month or two months later than the peak in urinary calcium. Thus, vitamin $\mathrm{D}$ may be only partly responsible for the summer rise in urinary calcium.

Whatever the reason for the seasonal variation in urinary calcium our observations have wide implications in the many areas of calcium metabolism where measurements of the urinary calcium level are used to assess the efficacy of a par- ticular treatment. This applies especially to treatment of calcium stone disease where many therapies include measures designed to reduce uninary calcium. Clearly, not only in studies where the patient acts as his own control but also in studies involving the use of normal healthy subjects as controls, care must be taken with the design of the experiment to ensure that comparisons are made at comparable seasons of the year.

\section{References}

Aaron, J., Gallagher, J. C., and Nordin, B. E. C. (1974). Lancet, 9, 84.

Bulusu, L., et al. (1970). Clinical Science, 38, 601.

Davis, R. H., Morgan, D. B., and Rivlin, R. S. (1970). Clinical Science, 39, 1. Fales, F. W. (1964). Clinical Chemistry, 10, 549.

Hodgkinson, A., and Pyrah, L. N. (1958). British fournal of Surgery, 46, 10. Kodicek, E., Lawson, D. E. M., and Wilson, P. W. (1970). Nature, 228, 763. McCance, R. A., and Widdowson, E. M. (1943/4). Fournal of Physiology, 102, 42 .

McLaughlin, M., et al. (1974). Lancet, 1, 536.

Morgan, D. B., Rivlin, R. S., and Davis, R. H. (1972). American fournal of Clinical Nutrition, 25, 652.

Omdahl, J., et al. (1971). Biochemistry, 10, 2935.

Peacock, M., and Nordin, B. E. C. (1969). In Proceedings of the Renal Stone Symposium, ed. A. Hodgkinson and B. E. C. Nordin, p. 253. London, Churchill.

Robertson, W. G., and Morgan, D. B. (1972). Clinica Chimica Acta, 37, 503. Stamp, T. C. B., and Round, J. M. (1974). Nature, 247, 563.

\title{
Bites by the Saw-scaled or Carpet Viper (Echis carinatus): Trial of Two Specific Antivenoms
}

\author{
D. A. WARRELL, N. McD DAVIDSON, L. D. OMEROD, HELEN M. POPE, \\ BARBARA J. WATKINS, B. M. GREENWOOD, H. A. RIED
}

British Medical fournal, 1974, 4, 437-440

\section{Summary}

Echis carinatus is the most important cause of morbidity and mortality from snake bite in Nigeria and in many other parts of the world. Forty-six patients with systemic poisoning by this snake were given echis antivenom made either by the South African Institute for Medical Research (S.A.I.M.R.) or by Behringwerke (North and West African polyvalent antivenom). A simple test of blood coagulability was used to assess whether an adequate neutralizing dose of antivenom had been given. An average of $15.2 \mathrm{ml}$ S.A.I.M.R. antivenom restored normal coagulability permanently in all 23 patients in one group, but in the other group receiving an average dose of $37.9 \mathrm{ml}$ Behringwerke antivenom normal clotting resulted in only 18 out of 23 patients. Local tissue swelling was similar in both groups, but local necrosis occurred in

Department of Medicine, Ahmadu Bello University, Zaria, Nigeria D. A. WARRELL, D.M., M.R.C.P., Consultant Physician (Present address: Hammersmith Hospital, London $\mathrm{W} 12$ 0HS)

N. McD. DAVIDSON, B.M., M.R.C.P., Senior Lecturer in Medicine L. D. OMEROD, M.B., D.T.M.\&.H., Medical Registrar HELEN M. POPE, Superintendent Technician HELEN M. POPE, Superintendent Tech

B. M. GREENWOOD, M.D., D.T.M.\&H., Senior Lecturer in Medicine

Liverpool School of Tropical Medicine, Liverpool L3 5QA

H. A. REID, M.D., F.R.C.P., Senior Lecturer in Tropical Medicine three patients treated with Behringwerke antivenom and in none given S.A.I.M.R. antivenom.

\section{Introduction}

The saw-scaled or carpet viper Echis carinatus (Schneider) fig. 1) is widely distributed throughout Africa north of the equator, the Middle East, Pakistan, India, and Sri Lanka. In this enormous area it is the most important cause of morbidity and mortality from snake bite in man. In parts of Nigeria, especially North Eastern and Benue Plateau States, $E$. carinatus bites are a serious medical problem. Several hospitals and dispensaries treat more than 150 victims each year with an overall mortality of 7-15\%. Before 1969 specific echis antivenom from the South African Institute of Medical Research (S.A.I.M.R.) was found to be very effective in rural mission hospitals. Subsequently it became difficult to import this antivenom into Nigeria and other echis antivenoms have been used, including Behringwerke North and West African polyvalent, Pasteur-Paris polyvalent and echis, and Razi Institute (Iran) echis antivenoms. The present study was prompted by reports that the mortality of echis bites treated at Guinter Memorial Hospital (Sudan Interior Mission), Bambur, North Eastern State had significantly increased as the availability of S.A.I.M.R. echis antivenom decreased (Arnett, 1971). We compared S.A.I.M.R. echis antivenom with Behringwerke North and West African polyvalent (bitis-echis-na ja) anti- 


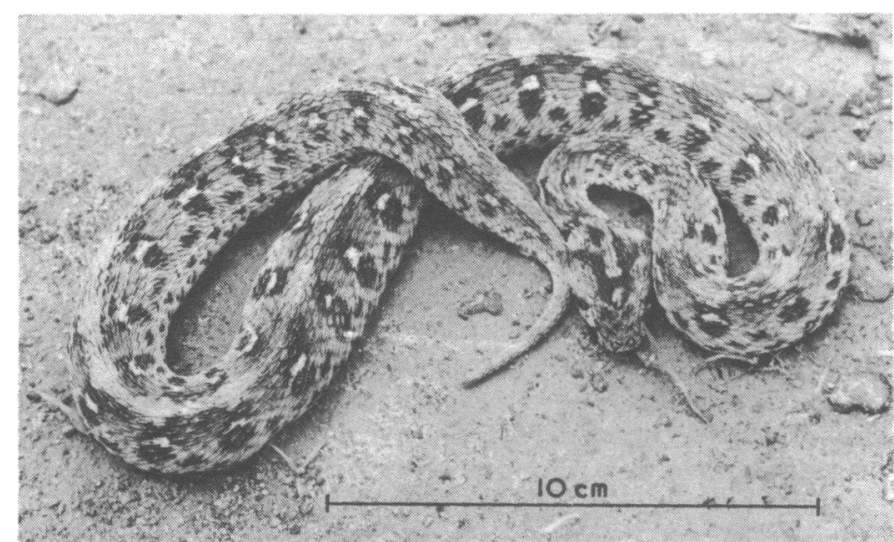

Saw-scaled or carpet viper, Echis carinatus (subspecies ocellatus). Live male specimen 54-cm long from Kaltungo, Nigeria.

venom, which is now the most widely used antivenom in Nigeria and Ghana.

\section{Patients and Methods}

\section{PATIENTS}

Forty-six patients were studied at Gombe and at Kaltungo General Hospitals, North Eastern State, in July and August 1973. In all cases the biting species was identified as $E$. carinatus, either because the snake was brought or by immunologicl tests of wound aspirate (Greenwood, et al., 1974). The blood was incoagulable, indicating systemic poisoning, and antivenom had not been given previously. Patients with evidence of complications, such as bleeding for more than 24 hours, evidence of cerebral haemorrhage, severe anaemia (haematocrit reading below $25 \%$ ), or shock were excluded from the trial and were treated immediately with S.A.I.M.R. antivenom. Allocation of patients was randomized to the Behringwerke or to the S.A.I.M.R. treatment group.

\section{ASSESSMENT}

Symptoms and signs were recorded on standard forms. Tooth sockets, nose, conjunctivae, optic fundi, sputum and saliva, urine, vomitus, and stools were examined for evidence of spontaneous haemorrhage. The amount of local swelling was assessed by circumference measurements as described elsewhere (Reid et al., 1963 a). The circumference-increase total at all four measurement sites-was also expressed as a percentage of the total circumference of the control limb. The extent of local swelling was graded from 1 (swelling confined to the bitten segment of limb) to 6 (swelling involving the whole limb and extending to the trunk). Venous blood was taken on admission for measurement of whole-blood clotting time (Biggs, 1972) and clot quality (Reid et al., 1963 b); platelet count (Thomson, 1970); haematocrit reading; and measurement of fibrin degradation products (F.D.P.) by tanned red cell haemagglutination-inhibition immunoassay (Wellcome $\mathbf{R e}$ agents Ltd.) and fibrinogen by radial immunodiffusion before and after clotting with thrombin (Warrell et al., 1974). Tests were repeated at six-hourly intervals until a full-volume clot formed during the clotting time procedure. Subsequently, patients were tested daily until discharged from hospital.

\section{TREATMENT}

Blood incoagulability seems to be the most sensitive indicator of systemic poisoning by $\boldsymbol{E}$. carinatus bites (Warrell et al., 1974). Preliminary studies in patients had indicated: (a) 10 ml of S.A.I.M.R. antivenom sometimes restored blood coagulability to normal; (b) if blood sampled six hours after a particular dose of antivenom did not clot more antivenom would be needed to restore normal clotting; and (c) in patients with similar severity of envenoming at least twice as much Behringwerke antivenom as S.A.I.M.R. antivenom was needed to rectify clotting. According to their treatment group, therefore, patients were given either $20 \mathrm{ml}$ Behringwerke antivenom (batch 1576, prepared 15 September 1972) or $10 \mathrm{ml}$ S.A.I.M.R. antivenom (batch 0938, prepared March 1973) by intravenous injection over 10 minutes. Six hours later absence of any whole-blood clot formation indicated inadequate dosage and the dose of antivenom was repeated. Formation of anything less than a full-volume clot postponed the decision for a further six hours. Unless a full-volume clot was formed on that occasion the antivenom dose was repeated. Clotting tests were performed at six-hourly intervals and more doses of antivenom were given until a full-volume clot was formed.

Codeine phosphate tablets were given for pain. No local treatment was given apart from resting the bitten limb, but when necrosis developed penicillin was given by injection and the necrotic tissue was removed as early as possible. Subcutaneous adrenaline and intravenous antihistamine and hydrocortisone were given for immediate serum reactions, and prednisone tablets were used when serum sickness developed. No other treatment was given.

\section{Results}

\section{COMPARABILITY OF THE TWO TREATMENT GROUPS}

Patients allocated to the Behringwerke and S.A.I.M.R. groups were found to be comparable in age, sex, tribe, size, time interval between being bitten and receiving the first dose of antivenom, and in severity of poisoning as judged clinically and from investigations (table $\mathrm{I}$ ).

TABLE I-Comparison of Two Treatment Groups of 23 Patients each before Antivenom Treatment

\begin{tabular}{|c|c|c|c|c|c|c|}
\hline & & & & & $\begin{array}{l}\text { Behringwerke } \\
\text { Antivenom }\end{array}$ & $\begin{array}{l}\text { S.A.I.M.R. } \\
\text { Antivenom }\end{array}$ \\
\hline 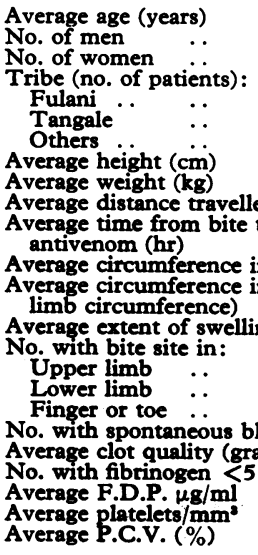 & $\begin{array}{l}\ldots \\
\ldots \\
\ldots \\
\ldots \\
\ldots \\
\ldots \\
\text { led to ho } \\
\text { to first } \\
\text { increase } \\
\text { increase } \\
\text { ing (grac } \\
\ldots \\
\ldots \\
\ldots \\
\text { oleeding } \\
5 \% \text { norn } \\
\ldots \\
\ldots \\
. .5\end{array}$ & $\begin{array}{l}\cdots \\
\cdots \\
\cdots \\
\cdots \\
\cdots \\
\cdots \\
\text { iospit } \\
\text { dose } \\
\ddot{e}(\mathrm{~cm}) \\
\text { e }(\%\end{array}$ & $\begin{array}{l}\because \\
\cdots \\
\ldots \\
\ldots \\
\because \\
\text { (miles) } \\
\text { f } \\
\ldots \\
\text { f control } \\
\cdots\end{array}$ & 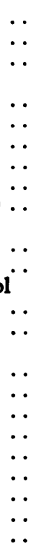 & $\begin{array}{c}26 \\
18 \\
5 \\
11 \\
6 \\
6 \\
153 \\
44 \\
18 \cdot 2 \\
10 \\
7 \cdot 3 \\
8 \cdot 9 \\
3 \cdot 0 \\
4 \\
19 \\
5 \\
14 \\
4 \cdot 8 \\
20 \\
1,970 \\
187,730 \\
38 \cdot 7\end{array}$ & $\begin{array}{c}23 \\
16 \\
7 \\
13 \\
6 \\
4 \\
155 \\
42 \\
18 \cdot 2 \\
9 \cdot 4 \\
6 \cdot 7 \\
7 \cdot 8 \\
2 \cdot 6 \\
2 \\
21 \\
5 \\
10 \\
4 \cdot 7 \\
19 \\
1,805 \\
196,700 \\
38 \cdot 8\end{array}$ \\
\hline
\end{tabular}

\section{EFFEGTS OF ANTIVENOM}

Clinical Effects.-Local swellings were not significantly different in the two groups (table II). Six of the patients treated initially with Behringwerke antivenom developed blisters at the bite site, and three of these subsequently had tissue necrosis. In the S.A.I.M.R. group only one patient had a blister and none showed necrosis. Spontaneous bleeding from sites that could easily be observed, such as tooth sockets, stopped within two hours of treatment in all cases and in some cases stopped spontaneously between admission and the first dose of antivenom. One patient developed severe headache and became confused four hours after her first dose of 
TABLE II-Effects of Antivenom in Two Treatment Groups

\begin{tabular}{|c|c|c|}
\hline & $\begin{array}{l}\text { Behringwerke } \\
\text { Antivenom }\end{array}$ & $\begin{array}{l}\text { S.A.I.M.R. } \\
\text { Antivenom }\end{array}$ \\
\hline 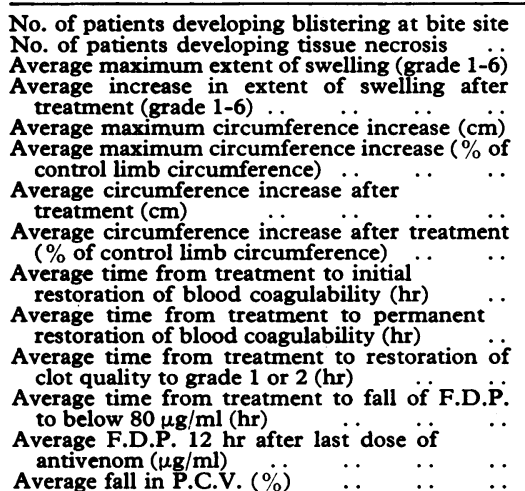 & $\begin{array}{c}6 \\
3 \\
3 \cdot 7 \\
0 \cdot 7 \\
10 \cdot 8 \\
13 \cdot 0 \\
3 \cdot 4 \\
4 \cdot 0 \\
14 \cdot 8 \\
27 \cdot 2 \\
44 \cdot 7 \\
130 \cdot 7 \\
345 \\
3 \cdot 5\end{array}$ & $\begin{array}{c}1 \\
0 \\
3 \cdot 1 \\
0 \cdot 5 \\
9 \cdot 4 \\
10 \cdot 8 \\
2 \cdot 8 \\
3 \cdot 1 \\
11 \cdot 8 \\
11 \cdot 8 * \\
29 \cdot 7 \\
92 \cdot 6 \\
73 * \\
2 \cdot 6\end{array}$ \\
\hline
\end{tabular}

Difference was significant: $\mathbf{P}=0.005$.

Behringwerke antivenom. She was later shown to have had a subarachnoid haemorrhage, from which she recovered. She required a total of $60 \mathrm{ml}$ Behringtwerke antivenom before slotting became normal. We have insufficient information about spontaneous haemorrhage to compare the two groups statistically.

Coagulation Defect.-In the 23 patients given S.A.I.M.R. antivenom normal blood clotting was permanently restored after an average dose of $15.2 \mathrm{ml}$. In the other group an average of $37.9 \mathrm{ml}$ of Behringwerke antivenom was given but normal clotting was permanently restored in only 18 out of 23 . In the remaining five cases (treatment failures) there was either failure to restore coagulability or recurrence of incoagulability 47-98 hours after starting treatment. They were then given 10-30 ml S.A.I.M.R. antivenom, which in all cases proved effective in restoring coagulability permanently within six hours (table III). S.A.I.M.R. antivenom restored blood coagulability significantly more rapidly than did Behringwerke (table II), but this depended on the somewhat arbitrary choice of incremental dose of the two antivenoms. Thus, if the incremental dose of Behringwerke had been higher venom neutralization might have been achieved more quickly. The F.D.P. level 12 hours after the last dose of antivenom was significantly lower in the S.A.I.M.R. than Behringwerke group, suggesting a more rapid cessation of defibrinogenation. The mean values for other measures of speed of response to antivenom were all lower in the S.A.I.M.R. group, but the differences were not statistically significant.

TABLE III-Doses of Behringwerke and S.A.I.M.R. Antivenoms required to Restore Blood Coagulability in 46 Patients

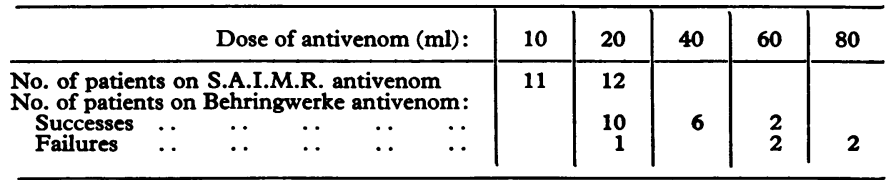

Serum Reactions.-Immediate-type hypersensitivity reactions were seen in six patients given Behringwerke and in four given S.A.I.M.R. antivenom, an overall incidence of $22 \%$. Of the five patients who had both types of antivenom (the treatment failures) one reacted to both types, two reacted to neither. One patient who received a tatal of $110 \mathrm{ml}$ of Behringwerke and S.A.I.M.R. antivenom showed immediatetype hypersensitivity on two occasions and finally developed serum sickness on the ninth day after the first dose of Behringwerke antivenom.

\section{Discussion}

E. carinatus venom can have at least four important effects in man (Warrell et al., 1974): local tissue swelling, local necrosis, incoagulable blood resulting from defibrinogenation, and spontaneous bleeding from small blood vessels. Cerebral haemorrhage is the most frequent cause of death and may occur two to seven days after the bite (Warrell et al., 1974; Salou, 1951). The relative importance of the procoagulant (causing defibrinogenation) and haemorrhagin (damaging small blood vessels) fractions of $E$. carinatus venom in the pathogenesis of spontaneous haemorrhage in human victims is uncentain. The ultimate control for a study of the effect of antivenom is comparison with the natural history in untreated subjects, but the danger of fatal spontaneous haemorrhage precludes such a study when specific antivenom is available. Patients with systemic poisoning after $E$. carinatus bites are in danger of fatal haemorrhage and urgently require an aedquate neutralizing dose of antivenom. Because of the expense of antivenom and the incidence of serum reactions it is highly desirable to control antivenom dosage in some way. Unfortunately haemorrhagin activity may be difficult to detect or assess. In contrast finding out whether the blood is non-clotting is a simple and very sensitive test of systemic poisoning. Though simple clotting tests may not directly reflect the vasculotoxic venom activity causing haemorrhage we have never seen spontaneous bleeding occurring in $E$. carinatus envenoming at a time when the blood was coagulable. The diagnostic value of simple tests of blood coagulability in assessing viperine poisoning has been described previously (Reid et al., 1963 b; Ahuja and Singh, 1951), but the use of these tests in controlling dosage of antivenom has not been emphasized.

The simple test of blood clotting used in this study is practicable in the rural hospitals and dispensaries where most victims of $E$. carinatus bite are seen. Venous blood is put into a clean glass vessel and left at room temperature for 20 minutes. It either clots or it does not clot; the clotting time is irrelevant. This test should be repeated six hours after each dose of antivenom until clotting is restored. After that daily tests should be done for at least three days to detect recurrent incoagulability which may be due to absorption of more venom from the bite site.

S.A.I.M.R. antivenom seemed to reverse the haematological abnormalities more rapidly and at a lower dosage than did Behringwerke antivenom. The values for speed of permanent restoration of normal clotting and fall of F.D.P. levels reached statistical significance. An average dose of $15.2 \mathrm{ml}$ S.A.I.M.R. antivenom restored coagulability permanently and this antivenom was also effective in the five patients treated unsuccessfully with Behringwerke antivenom. The results suggested that S.A.I.M.R. antivenom also prevented local necrosis though the numbers were too small to confirm this statistically. If further observations confirm that antivenom reduces or prevents local tissue necrosis it would be a very important benefit because local necrosis can be a major problem in snake bite, causing prolonged morbidity and sometimes permanent disability.

Antigenic differences in $E$. carinatus venoms from different geographical areas of the snake's enormous range might explain the variable potency of particular specific echis antivenoms. Kornalik and Taborska (1973) reported significant qualitative differences in venoms from individual specimens of $E$. carinatus all caught in the same area. Latifi (1973) found that antivenoms raised against the venom of $E$. carinatus from one particular country might have little effect in neutralizing the venom of $E$. carinatus from another country. The subspecies responsible for biting our patients was $\boldsymbol{E}$. carinatus ocellatus (Stemmler) and its known distribution is confined to western Africa. Both antivenoms used in this trial were raised against venom from east African snakes. S.A.I.M.R. used E. carinatus venom from Ethiopia (Christen- 
sen, 1974). Behringwerke use venom of $E$. carinatus pyramidum (Geoffroy Saint Hilaire) from the Sudan, the electrophoretic pattern of which is very similar to that of Ethiopian venom (Behringwerke, 1974). Thus, geographical differences in venoms are unlikely to explain the difference in potency of these two antivenoms. A higher titre of specific antibody can be expected in monospecific as compared with polyspecific antivenom, but this difference should be overcome by using a higher dose. Our findings suggest that S.A.I.M.R. antivenom contains a specifically higher titre of neutralizing antibody directed against the procoagulant and perhaps the necrosis-inducing venom fractions.

This work was supported by the Wellcome Trust and H.A.R. was the recipient of a Welloome Research Travel Grant. Cotton and Agricultural Processors Ltd. (formerly B.C.G.A., Nigeria, Ltd.) at Zaria and Gombe provided invaluable help with housing and communications.

Dr. P. A. Christensen, Director of the South African Institute for Medical Research, generously donated supplies of S.A.I.M.R. antivenom for this study.

We thank the Chief Medical Officer, North Eastern State,
Nigeria (Dr. S. Hussain) for permission to conduct the studies at Gombe and Kaltungo General Hospitals, the medical superintendents of these hospitals (Drs. S. H. A. Lofty and I. F. Shoukry), the chief dispenser, Billiri-Kufai E.C.W.A. Dispensary (the late Mallam Sabo Tukub), and their staffs for help.

\section{References}

Ahuja, M. L., and Singh, G. (1951). Indian fournal of Medical Research, 42, 661

Arnett, C. (1971). Personal communication.

Behringwerke (1974). Personal communication.

Biggs, R. (1972). Human Blood Coagulation, Haemostasis and Thrombosis. Oxford, Blackwell.

Christensen, P. A. (1974). Personal communication.

Greenwood, B. M., et al. (1974). In preparation.

Kornalik, F., and Taborska, E. (1973). In Animal and Plant Toxins, ed. E. Kaiser, 99 . Munich, Goldmann.

Latifi, M. (1973). In Proceedings of the Ninth International Congress on Tropical Medicine and Malaria, abstract 107. Athens, 14-21 October.

Reid, H. A., Thean, P. C., and Martin, W. J. (1963 a). British Medical fournal, 2, 1378 .

Reid, H. A., Chan, K. E., and Thean, P. C. (1963 b). Lancet, 1, 621.

Salou, G. (1951). Medecine Tropicale, 11, 655.

Thomson, J. M. (1970). A Practical Guide to Blood Coagulation and Haemostasis. London, Churchill

Warrell, D. A., et al. (1974). In preparation.

\title{
Indications for Systemic Antibiotic Prophylaxis in Neutropenic Patients
}

\author{
A. S. D. SPIERS, M. H. N. TATTERSALL, H. GAYA
}

British Medical fournal, 1974, 4, 440-441

\section{Summary}

Four patients with malignant blood disease and neutropenia developed apparently localized infective lesions of the skin or conjunctiva from which Pseudomonas aeruginosa was cultured. In spite of appropriate local antimicrobial treatment all patients developed pseudomonas septicaemia within a short period and three died. It is argued that the isolation of pseudomonads from apparently localized lesions in patients with compromised antibacterial defences is an indication for systemic antibiotic therapy.

\section{Introduction}

Few subjects are more contentious than the prophylactic use of antibiotics. Many studies have shown that the widespread use of prophylactic antibiotics may lead to more rather than less infection. In the immunodepressed or neutropenic patient chemoprophylaxis may delay the acquisition of infection, but when infection does occur in patients receiving antibiotics in this way it usually is caused by antibiotic-resistant organisms. Evidence favouring the use of prophylactic systemic antibiotics has been reported in patients subjected to caesarean section (Gibbs et al., 1972)

M.R.C. Leukaemia Unit and Department of Bacteriology, Roya Postgraduate Medical School, London W12 0HS

A. S. D SPIERS, PH.D. F.R.A.C.P., Consultant Physician

M. H. N. TATTERSALL, M.D., M.R.C.P., M.R.C. Clinical Research Fellow

H. GAYA, M.B., M.R.C.PATH., Consultant Bacteriologist (Present appointment: Reader in Bacteriology, Wright-Fleming Institute, London W2 1PG) and after removal of a perforated appendix (Magarey et al., 1971). In both groups of patients prophylactic antibiotics substantially reduced the infection rate, but the diagnosis of infection in both studies was based mainly on clinical criteria with bacteriological confirmation in only a few patients. After open heart sungery it is customary to administer prophylactic systemic antibiotics but the value of this policy has not been clearly established.

In patients with malignant blood disease and neutropenia infection is the leading cause of death (Hersh et al., 1965; Levine et al., 1972). The natural history of infection in these patients is one of rapid deterioration, and death often occurs before the infecting organism has been isolated (Schimpff et al., 1971). This has prompted us to advocate the empirical use of antibiotic combinations for episodes of presumed infection in these patients (Tattersall et al., 1972; Gaya et al., 1973; Tattersall et al., 1973), and this has been the subject of a recent symposium (European Fournal of Cancer, 1973). At present an international trial is in progress to establish which of three combinations of two antibiotics is the most effective initial therapy for presumed infection in this type of patient. Like other groups we are studying the prophylactic effect of decontaminating the intestinal contents by the oral administration of nonabsorbable antibiotics with the aim of reducing the incidence of septicaemias of enteric onigin. The use of prophylactic systemic antibiotics in patients with malignant blood disease and neutropenia is a separate consideration, and until now this has not been our policy. From routine surveillance cultures in certain patients, however, we have observed the presence of coliform organisms on the skin. These were not eradicated by local antiseptic treatment and were eventually the cause of septicaemia.

We describe here four patients with malignant blood disease whose clinical course prompts us to recommend the use of prophylactic systemic antibiotics in certain clearly 